\title{
Toughened Ceramics in the System $\mathrm{Al}_{2} \mathrm{O}_{3}: \mathrm{Cr}_{2} \mathrm{O}_{3} / \mathrm{ZrO}_{2}: \mathrm{HfO}_{2}$
}

\author{
T. Y. Tien, T. K. Brog and A. K. Li \\ Materials Science and Engineering, The University of Michigan, Ann Arbor, \\ Michigan 48109, USA
}

\begin{abstract}
$S U M M A R Y$
Composites of $\mathrm{Al}_{2} \mathrm{O}_{3}: \mathrm{Cr}_{2} \mathrm{O}_{3}$ solid solution matrix with $\mathrm{ZrO}_{2}: \mathrm{HfO}_{2}$ solid solution dispersed particles were prepared and their properties studied. Thermal conductivity of compositions containing $20 \mathrm{~mol} \%$ or more of chromia was found to be lower than that of partially stabilized zirconia at temperatures above $700^{\circ} \mathrm{C}$. Specimens in this system were annealed at $1000^{\circ} \mathrm{C}$ for longer than $500 \mathrm{~h}$ and no mechanical property degradation was observed. Modulus of elasticity, bend strength and fracture toughness of these composites depend strongly on composition, volume fraction, size and the crystallographic modification of the dispersed particles. Best average bend strength of the composites is $490 \mathrm{MPa}$ and the best average fracture toughness observed for these composites was $7 \cdot 4 \mathrm{MPa} \mathrm{m}^{1 / 2}$. It was found that the fracture toughness of some of the compositions increased with increasing temperature reaching a maximum of $300-500^{\circ} \mathrm{C}$, and returned to the room temperature value at $1000^{\circ} \mathrm{C}$. From the results obtained these composites can be considered as a potential candidate for advanced heat engine applications.
\end{abstract}

\section{INTRODUCTION}

Partially stabilized zirconia (PSZ) has been considered to be the leading candidate for the structural components of the adiabatic diesel engines. ${ }^{1}$ However, it has been demonstrated that the currently available PSZ deteriorates at the operating temperatures of the diesel engine in a time period which is much less than that required for automotive applications. ${ }^{2}$ 207

Int. J. High Technology Ceramics 0267-3762/86/\$03.50 (C) Elsevier Applied Science Publishers Ltd, England, 1986. Printed in Great Britain 
Alumina toughened with zirconia dispersions has been reported in the literature. ${ }^{3}$ The fracture toughness and bend strength of this material are sufficient for it to be considered as a candidate for heat engine applications. However, the thermal conductivity of this material is too high for insulation purposes. ${ }^{4}$ The fracture toughness of the alumina/zirconia composite decreases with increasing temperature ${ }^{5}$ and the toughening effect diminishes at the operating temperatures of the heat engines. It was suggested that this material be modified to reduce its thermal conductivity by solid solution formation (chromia in alumina) ${ }^{6}$ and the temperature dependence of the toughness modified by introducing hafnia in solid solution in the dispersed zirconia particles. It is known that the tetragonal-monoclinic transformation temperatures of the zirconia:hafnia solid solutions are higher than that of pure zirconia. ${ }^{7}$ In an effort to optimize the mechanical and physical properties of the possible candidate material for structural applications at elevated temperature, a research program was initiated to study the toughened ceramics in the system $\mathrm{Al}_{2} \mathrm{O}_{3}: \mathrm{Cr}_{2} \mathrm{O}_{3} / \mathrm{ZrO}_{2}: \mathrm{HfO}_{2}$. The ultimate goal of this project is to develop a material suitable for high temperature applications in advanced heat engines. This paper summarizes the results of these studies.

\section{EXPERIMENTS AND RESULTS}

Composite specimens in the system $\mathrm{Al}_{2} \mathrm{O}_{3}: \mathrm{Cr}_{2} \mathrm{O}_{3} / \mathrm{ZrO}_{2}: \mathrm{HfO}_{2}$ were prepared and their properties measured. The properties measured include: thermal conductivity, thermal stability, modulus of elasticity, bend strength and fracture toughness. The specimens were prepared by three different methods, detailed below, depending on the properties to be studied. The sintering and growth kinetics of both the matrix grains and the dispersed particles in the system were also studied in order to develop an optimum microstructure, and, consequently, optimum properties of the composites.

\subsection{Thermal conductivity}

Specimens for thermal conductivity measurements were hot pressed. Prereacted $\mathrm{Al}_{2} \mathrm{O}_{3}: \mathrm{Cr}_{2} \mathrm{O}_{3}$ and $\mathrm{ZrO}_{2}: \mathrm{HfO}_{2}$ powders were ball milled and hot pressed at $1500^{\circ} \mathrm{C}$ for $30 \mathrm{~min}$ under a uniaxial pressure of $35 \mathrm{MPa}$ using BN-coated graphite dies in a graphite resistance furnace. Thermal diffusivity of these specimens was measured by the 'laser flash' method. ${ }^{8}$ Literature data on specific heat were used and the thermal conductivities of these specimens were calculated. The results are given in Fig. 1. The thermal conductivities of some $\mathrm{PSZ}^{9}$ are also included in the figure for comparison. 


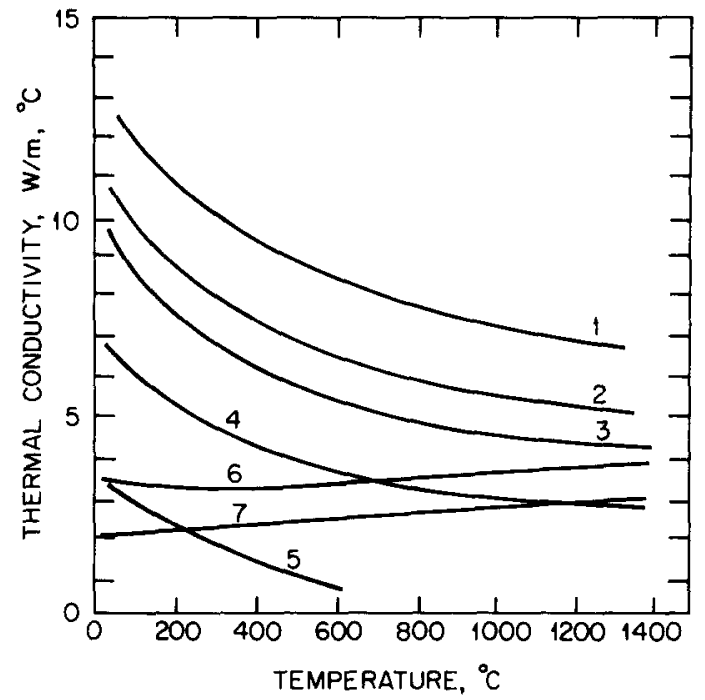

Fig. 1. Thermal conductivity of composites in the system $\mathrm{Al}_{2} \mathrm{O}_{3}: \mathrm{Cr}_{2} \mathrm{O}_{3} / \mathrm{ZrO}_{2}: \mathrm{HfO}_{2}$. Curve 1, hot pressed $\mathrm{Al}_{2} \mathrm{O}_{3}$; Curve 2, $\mathrm{Al}_{2} \mathrm{O}_{3} / 15 \mathrm{vol} \% \mathrm{ZrO}_{2} ;$ Curve $3, \mathrm{Al}_{2} \mathrm{O}_{3}: 20 \mathrm{~mol} \%$ $\mathrm{Cr}_{2} \mathrm{O}_{3} / 15$ vol $\% \mathrm{ZrO}_{2}$, fine grained; Curve 4, $\mathrm{Al}_{2} \mathrm{O}_{3}: 20 \mathrm{~mol} \% \mathrm{Cr}_{2} \mathrm{O}_{3} / 15$ vol\% $\mathrm{ZrO}_{2}$, coarse grained; Curve $5, \mathrm{Al}_{2} \mathrm{O}_{3}: 50 \mathrm{~mol} \% \mathrm{Cr}_{2} \mathrm{O}_{3} / 15 \mathrm{vol} \% \mathrm{ZrO}_{2}$, coarse grained; Curve 6 , $\mathrm{ZrO}_{2}: 3 \mathrm{~mol} \% \mathrm{Y}_{2} \mathrm{O}_{3}$, tetragonal; Curve $7, \mathrm{ZrO}_{2}: 6 \mathrm{~mol} \% \mathrm{Y}_{2} \mathrm{O}_{3}$, cubic.

\subsection{Mechanical properties}

Specimens for mechanical property measurements were prepared by dry pressing and sintering. Pre-reacted alumina:chromia and zirconia:hafnia solid solution powders were attrition milled separately ( in propanol). Submicron powders of both the matrix and the dispersed phases were mixed in a ball mill (in water). Dried mixtures were granulated ( -60 mesh) and isostatically pressed $(28 \mathrm{MPa})$ in thin rubber bags. Pellets, $10 \mathrm{~mm}$ in diameter and $5 \mathrm{~mm}$ thick, and round bars, $5 \mathrm{~mm}$ in diameter and $60 \mathrm{~mm}$ long, were made for characterization and property measurements. Dry pressed specimens were sintered at $1550^{\circ} \mathrm{C}$ for $2 \mathrm{~h}$ under an argon atmosphere in an induction furnace with a graphite susceptor. All of the specimens used for property measurements were fully dense.

The average size of the dispersed particles was measured by the linear intercept method ${ }^{10}$ and the results showed that the zirconia:hafnia particle size varied with the matrix composition and volume fraction of the dispersed phase. The results are given in Figs 2 and 3, respectively. The dispersed particles in all sintered specimens contain both tetragonal and monoclinic modifications of the zirconia. The fraction of the tetragonal phase $^{11}$ in the sintered specimens depends on the composition of the composites. Some of the results are given in Fig. 4. 


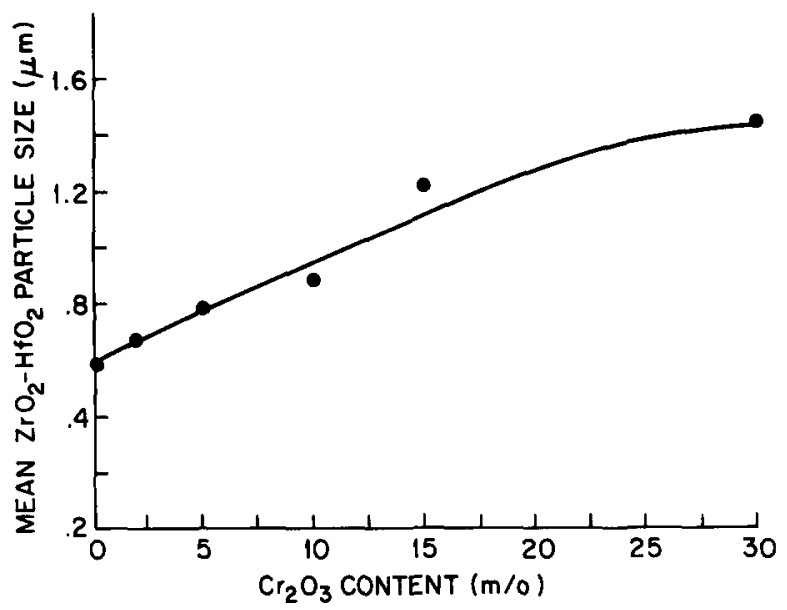

Fig. 2. Mean particle size of the dispersed phase as a function of the $\mathrm{Cr}_{2} \mathrm{O}_{3}$ content in the matrix phase. The composites contain $10 \mathrm{vol} \%$ of $\mathrm{ZrO}_{2}: 10 \mathrm{~mol} \% \mathrm{HfO}_{2}$.

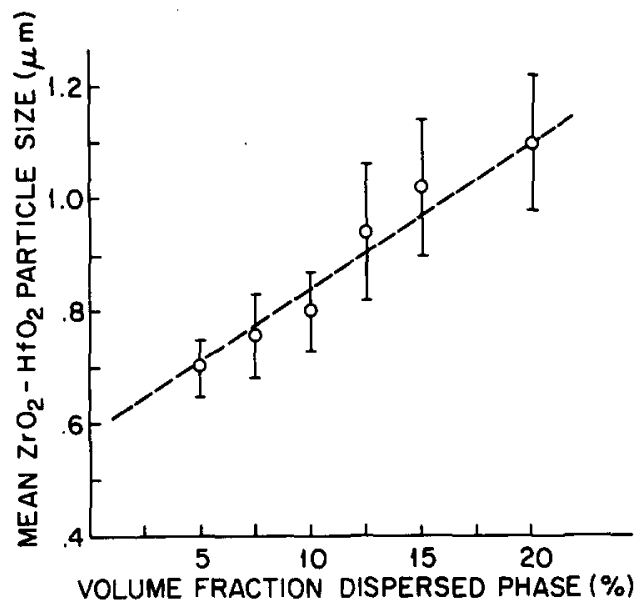

Fig. 3. Mean $\mathrm{ZrO}_{2}: \mathrm{HfO}_{2}$ particle size in the composites as a function of the volume fraction of the dispersed phase. The matrix phase contains $5 \mathrm{~mol} \%$ of $\mathrm{Cr}_{2} \mathrm{O}_{3}$ in $\mathrm{Al}_{2} \mathrm{O}_{3}$.

The elastic modulus of the sintered bars was measured using the sonic method.* Results of these measurements are given in Fig. 5. The modulus of the composites decreased as the amount of the dispersed phase increased following the rule of mixtures. ${ }^{5} \mathrm{~A}$ sudden decrease in the modulus was observed at high zirconia containing compositions. The drop of the modulus at the high dispersed phase containing compositions indicates the

* Modulus measurements were made by Dr L. Schioler of the Army Materials Technology Laboratory. 


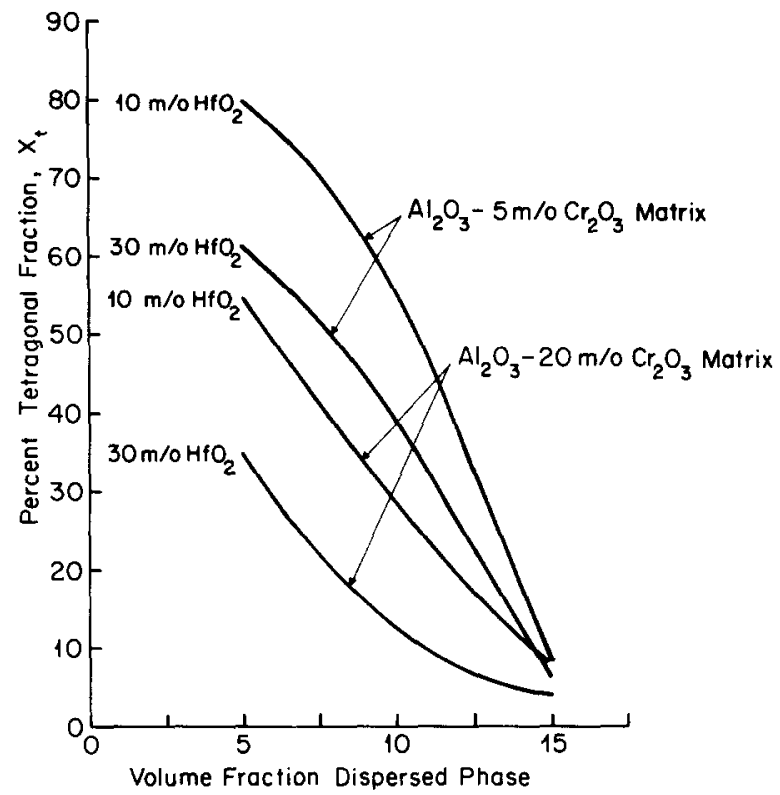

Fig. 4. Tetragonal fraction of the $\mathrm{ZrO}_{2}: \mathrm{HfO}_{2}$ dispersed phase in the composites.

existence of microcracks in the specimens. ${ }^{5}$ The microcracks are the result of the volume change ${ }^{12}$ of the dispersed particles during the tetragonalmonoclinic transformation. For composites containing the same volume fraction of dispersed phase, the composite containing $30 \mathrm{~mol} \%$ of hafnia in solid solution with zirconia has a higher modulus than that of the specimens containing $10 \mathrm{~mol} \%$ of hafnia. This indicates that the $30 \mathrm{~mol} \%$ hafnia samples contain a lower density of microcracks. The specimens

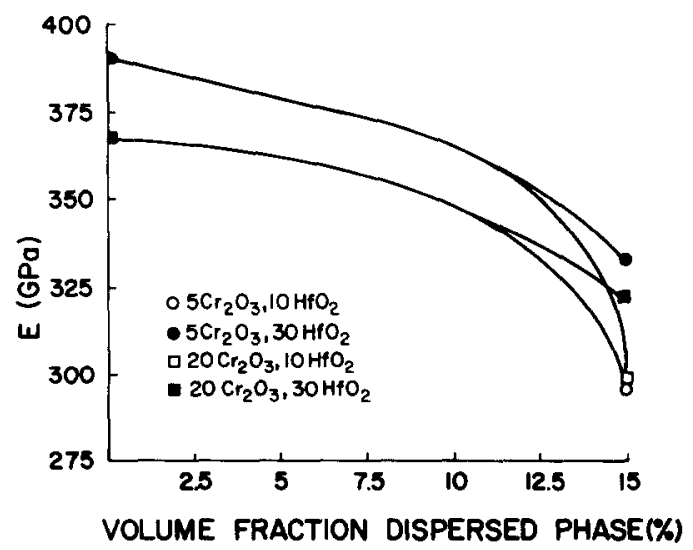

Fig. 5. Elastic modulus of the composites as a function of volume fraction of the dispersed particles. 
used for the strength measurements were machined to a nominal dimension of $2.06 \times 2.80 \times 50 \mathrm{~mm}^{3}$. The test fixture has an inner span of $9.5 \mathrm{~mm}$ and an outer span of $19.0 \mathrm{~mm}$. The results of the 4-points bend strength measurements (average values of 6 or more tests for each composition) are given in Fig. 6. Similar to the modulus measurements, the strength of $30 \mathrm{~mol} \%$ hafnia specimens at higher volume fractions of dispersed phase is higher than that of the $10 \mathrm{~mol} \%$ hafnia samples. These results suggested

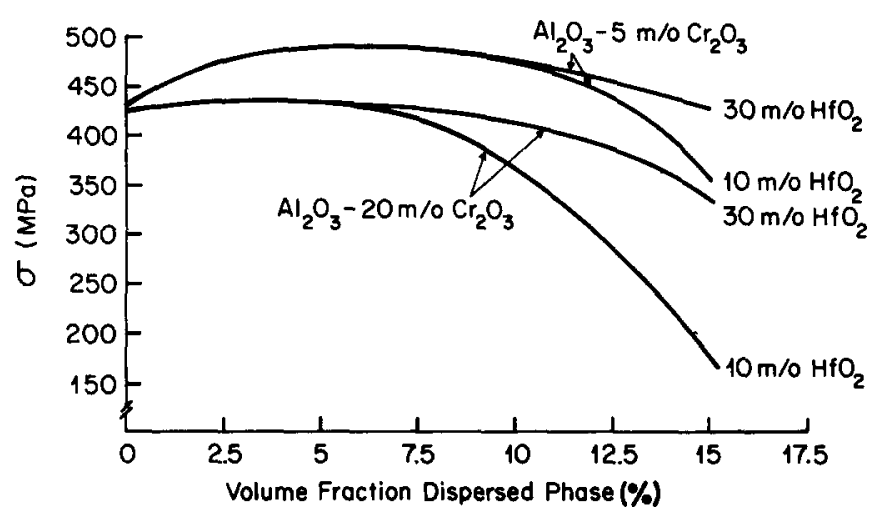

Fig. 6. Bend strength of the composites as a function of volume fraction of the dispersed particles.

that the $30 \mathrm{~mol} \%$ hafnia samples contained a lower density of microcracks than the $10 \mathrm{~mol} \%$ hafnia samples. This can be interpreted as showing that the volume change during the tetragonal-monoclinic transformation is lower for the higher hafnia containing zirconia solid solution particles than that of the lower hafnia containing zirconia solid solutions. The volume change of the solid solution particles during phase transformation was measured by thermal expansion of the composites. ${ }^{13}$

Fracture toughness was measured by the indentation in bend strength method. ${ }^{14}$ The results are given in Fig. 7. The toughness value of the specimens increased as a function of volume fraction of the dispersed phase and declined after reaching a maximum.

Combining the data in Fig. 7 and Fig. 4, a graph as shown in Fig. 8 was obtained. This graph suggested that higher toughness values could be obtained for compositions containing 10, 12.5 and $15 \mathrm{vol} \%$ disperse phase by reducing the value of the volume of the monoclinic phase $\left(X_{\mathrm{m}} V_{\mathrm{f}}\right)$. For specimens with a constant volume fraction of the dispersed particles $\left(V_{f}\right)$, the $X_{\mathrm{m}} V_{\mathrm{f}}$ value can be reduced by reducing the fraction of the monoclinic form $\left(X_{\mathrm{m}}\right)$ of the dispersed zirconia phase. For a given $V_{f}$, when $X_{\mathrm{m}} V_{\mathrm{f}}=V_{\mathrm{f}} / 2$, a maximum on the toughness curve can be expected. 


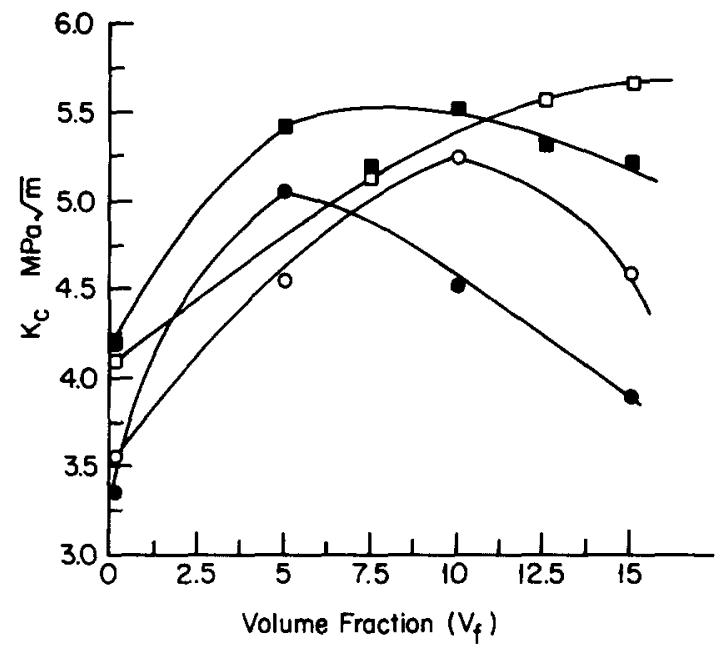

Fig. 7. Fracture toughness of the composites as a function of the volume fraction of the dispersed particles. $\mathrm{O}, \mathrm{Al}_{2} \mathrm{O}_{3}: 20 \mathrm{~mol} \% \mathrm{Cr}_{2} \mathrm{O}_{3} / \mathrm{ZrO}_{2}: 10 \mathrm{~mol} \% \mathrm{HfO}_{2} ; \mathrm{O}, \mathrm{Al}_{2} \mathrm{O}_{3}: 20 \mathrm{~mol} \%$ $\mathrm{Cr}_{2} \mathrm{O}_{3} / \mathrm{ZrO}_{2}: 30 \mathrm{~mol} \% \quad \mathrm{HfO}_{2} ; \square, \quad \mathrm{Al}_{2} \mathrm{O}_{3}: 5 \mathrm{~mol} \% \quad \mathrm{Cr}_{2} \mathrm{O}_{3} / \mathrm{ZrO}_{2}: 10 \mathrm{~mol} \% \quad \mathrm{HfO}_{2}$; $\mathrm{Al}_{2} \mathrm{O}_{3}: 5 \mathrm{~mol} \% \mathrm{Cr}_{2} \mathrm{O}_{3} / \mathrm{ZrO}_{2}: 30 \mathrm{~mol} \% \mathrm{HFO}_{2}$.

Comparing Figs 2, 3 and Fig. $4, X_{\mathrm{m}}$ can be reduced by reducing the mean particle size of the dispersed phase.

\subsection{Thermal stability}

Specimens of alumina, 10 and $20 \mathrm{~mol} \%$ chromia in the matrix phase containing $10 \mathrm{vol} \%$ of 10 and $20 \mathrm{~mol} \%$ hafnia containing zirconia particles, were held at $1000^{\circ} \mathrm{C}$ for more than $500 \mathrm{~h}$ in air and no degradation

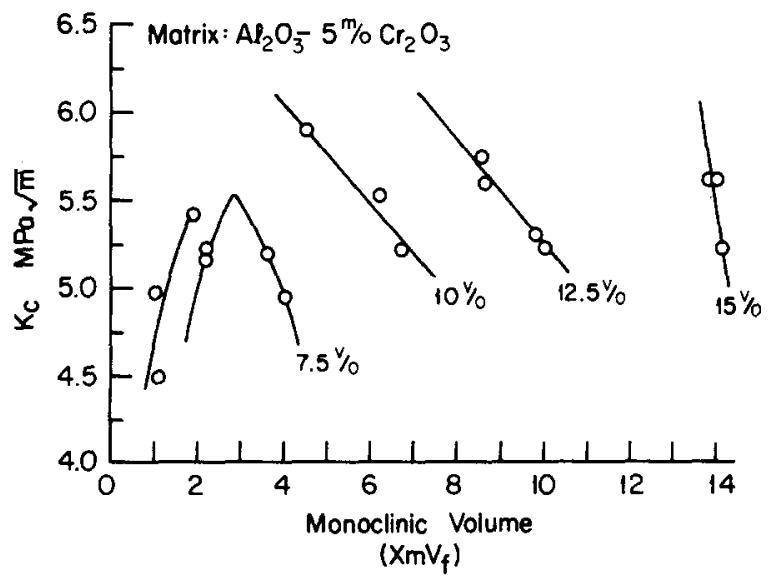

Fig. 8. Fracture toughness of the composites as a function of the monoclinic volume of the dispersed $\mathrm{ZrO}_{2}: \mathrm{HfO}_{2}$ particles. 


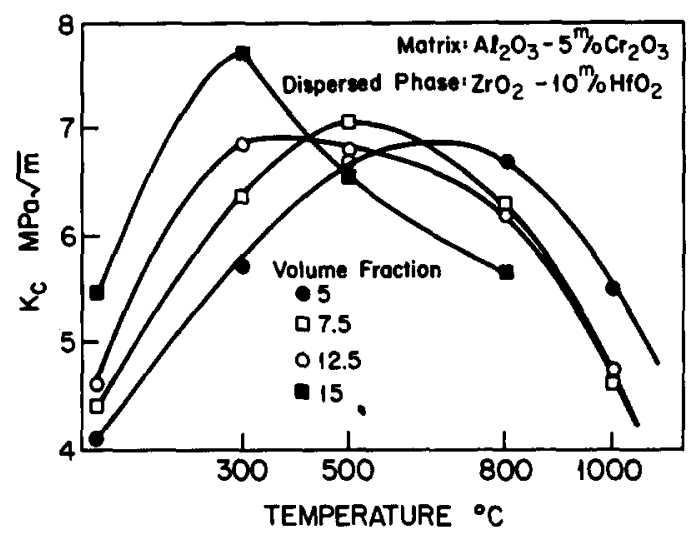

Fig. 9. Temperature dependence of the fracture toughness of composites.

in density, elastic modulus, bend strength and fracture toughness was observed. ${ }^{15}$

\subsection{Temperature dependence of fracture toughness}

The fracture toughness of some compositions was measured at elevated temperatures. These results are given in Fig. 9. The fracture toughness was measured using the indentation-strength-in-bend test. ${ }^{14}$ The mechanism for the toughness increase with increasing temperature is not understood at this time.

\subsection{Sintering and growth kinetics of the matrix grains and dispersed particles}

Starting powders for these studies were prepared by coprecipitation. Aqueous solutions of aluminum nitrate, chromium nitrate, zirconium oxychloride and hafnium oxychloride were mixed in ratios according to the compositions to be prepared. The mixed metal ions were precipitated by $\mathrm{NH}_{4} \mathrm{OH}$ solution. Precipitates were dried and calcined at $1050^{\circ} \mathrm{C}$ to convert the hydroxides to oxides. Calcined powders were isostatically pressed and sintered in an induction furnace using a graphite susceptor. The densities of the sintered specimens were measured by Archimedes' principle. The results indicated that specimens sintered at $1550^{\circ} \mathrm{C}$ reached the theoretical density when the furnace reached the sintering temperature without holding time. Polished surfaces were thermally etched and the grain sizes and particle sizes were measured by the linear intercept technique. ${ }^{10}$ The results are given in Fig. 10. These show that composites with a mean zirconia particle size smaller than $0.5 \mu \mathrm{m}$ can be obtained in fully dense samples. 


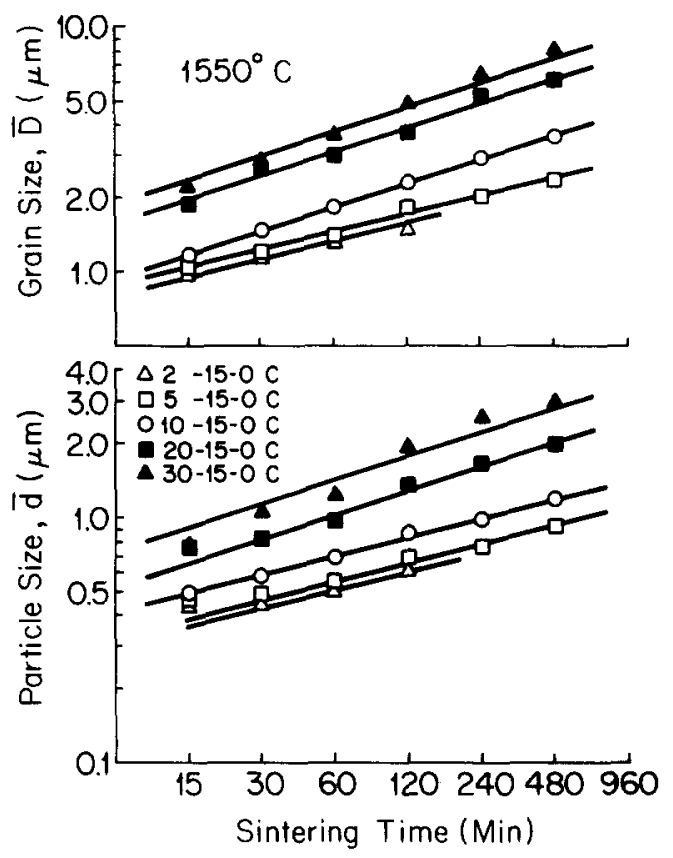

Fig. 10. Matrix grain and dispersed particle growth kinetics for composites containing $15 \mathrm{vol} \%$ of dispersed particles, sintered at $1550^{\circ} \mathrm{C}$. Composition designation: $\mathrm{Cr}_{2} \mathrm{O}_{3}$ content-vol $\% \mathrm{ZrO}_{2}-\mathrm{HfO}_{2}$ content.

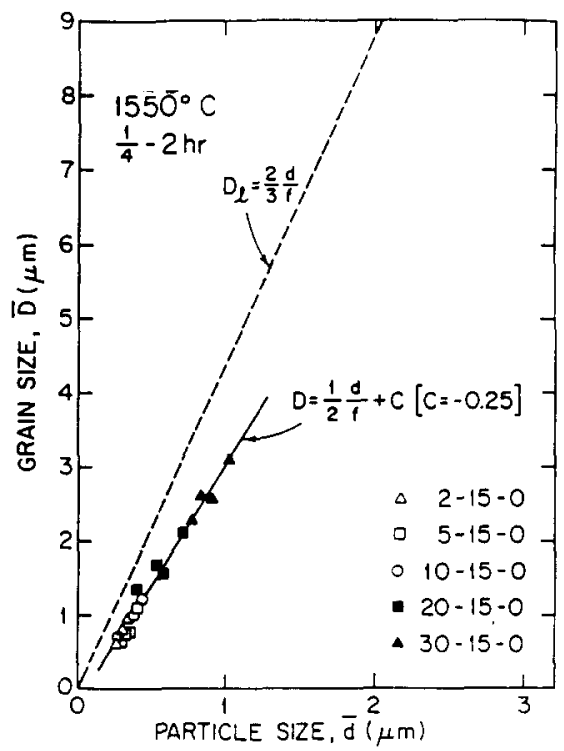

Fig. 11. Grain size vs particle size for specimens sintered at $1550^{\circ} \mathrm{C}$. Composition designation: $\mathrm{Cr}_{2} \mathrm{O}_{3}$ content-vol $\% \mathrm{ZrO}_{2}-\mathrm{HfO}_{2}$ content. 
Growth kinetics of the matrix grains and the dispersed particles were also measured at $1450,1500,1550$ and $1600^{\circ} \mathrm{C}$. The results are reported in Table 1 in the form of:

$$
\ln \left(D / t^{n}\right)=\ln D_{0}-Q / R T \quad \text { and } \quad \ln \left(d / t^{n}\right)=\ln d_{0}-Q / R T
$$

where $D$ is the grain size of the matrix phase, $d$ is the particle size of the dispersed phase, $n$ is the time exponent, $Q$ is activation energy for growth, $R$ is the gas constant, and $T$ is absolute temperature.

Grain sizes are plotted against the particle sizes in Fig. 11. This shows a straight line relationship. This relationship follows Zener's suggestion ${ }^{16}$ that the limiting grain size $\left(D_{\mathrm{f}}\right)$ is related to the size of the inclusions $(d)$ and their volume fraction $(f)$ in a composite following the form: $D_{\mathrm{f}}=d / f$.

As shown in Table 1, both the grain and the particle growth rates

TABLE 1

The Growth Rates of the Matrix Grains and the Dispersed Particles Expressed in the Form of $\ln \left(D / t^{n}\right)=\ln$

\begin{tabular}{ccccc}
\multicolumn{5}{c}{$D_{0}-(Q / R T)$} \\
\hline Composition $^{\alpha}$ & $n$ & $\ln D_{0}$ & $Q$ & $\begin{array}{c}\text { Correlation } \\
\text { coefficient }\end{array}$ \\
\hline \multicolumn{3}{c}{ For matrix grains: } \\
$2-15-0$ & 0.213 & 1.608 & 44.4 & -0.999 \\
$5-15-0$ & 0.244 & 4.580 & 55.5 & -0.957 \\
$10-15-0$ & 0.324 & 0.422 & 42.2 & -0.999 \\
$20-15-0$ & 0.339 & 7.264 & 65.7 & -0.999 \\
$30-15-0$ & 0.385 & 10.839 & 79.5 & -0.998 \\
$0-15-10$ & 0.230 & 11.474 & 33.7 & -0.962 \\
$0-15-20$ & 0.230 & 11.474 & 33.7 & -0.962 \\
$0-15-30$ & 0.230 & 11.474 & 33.7 & -0.962
\end{tabular}

For dispersed particles:

$\begin{array}{rrrrr}2-15-0 & 0.140 & 3.275 & 51.5 & -0.975 \\ 5-15-0 & 0.207 & 1.314 & 45.9 & -0.947 \\ 10-15-0 & 0.253 & 2.071 & 49.3 & -0.961 \\ 20-15-0 & 0.296 & 6.199 & 64.4 & -0.993 \\ 30-15-0 & 0.408 & 7.660 & 72 \cdot 1 & -0.986 \\ 0-15-10 & 0.143 & -4.137 & 27.8 & -0.990 \\ 0-15-20 & 0.143 & -4.137 & 27.8 & -0.990 \\ 0-15-30 & 0.143 & -4.137 & 27.8 & -0.990\end{array}$

${ }^{a}$ Composition designations: $X-Y-Z . \quad X=\mathrm{mol} \%$ of $\mathrm{Cr}_{2} \mathrm{O}_{3}$ in the matrix $\mathrm{Al}_{2} \mathrm{O}_{3}$ solid solution phase, $Y=v o l \%$ of dispersed phase in the composites, and $Z=\mathrm{mol} \%$ of $\mathrm{HfO}_{2}$ in the dispersed $\mathrm{ZrO}_{2}$ solid solution phase. 


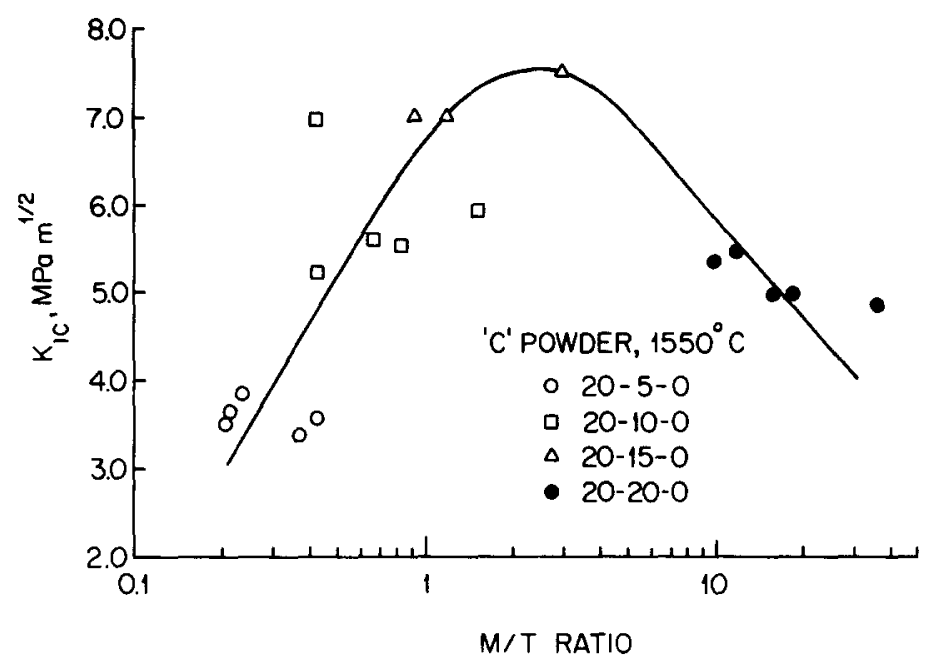

Fig. 12. Fracture toughness of composites as a function of monoclinic to tetragonal ratio of the dispersed $\mathrm{ZrO}_{2}$ particles. Specimens were prepared using coprecipitated powders as precursors. The composition identification: The first number indicates $\mathrm{mol} \%$ of $\mathrm{Cr}_{2} \mathrm{O}_{3}$ in $\mathrm{Al}_{2} \mathrm{O}_{3}$ and the second number indicates vol\% of the dispersed phase in the composite.

(For instance $20-15$ indicates $20 \mathrm{~mol}$ of $\mathrm{Cr}_{2} \mathrm{O}_{3}$ in $\mathrm{Al}_{2} \mathrm{O}_{3}$ and $15 \mathrm{vol} \%$ of $\mathrm{ZrO}_{2}$.)

increased as the chromia contents in the matrix phase increased, whereas the growth rate of the particles remained unchanged while the hafnia content changed in the dispersed phase. This result suggested that Ostwald ripening played a less important role in the particle growth than the coalescence. ${ }^{17}$

The fracture toughness of some specimens was measured. The tetragonal zirconia contents were measured and the results indicated that higher toughness values were observed when the zirconia particles had a monoclinic to tetragonal ratio in the range of $1: 1$ to $1: 2$ (Fig. 12). These results indicated that multiple toughening mechanisms are active in this system. At lower monoclinic zirconia volume, stress-induced transformation toughening and crack deflection are active, and for high monoclinic zirconia volume, microcrack nucleation/growth and crack deflection are active. ${ }^{13}$

\section{CONCLUSION}

The modulus of elasticity, bend strength and fracture toughness of composites composed of an $\mathrm{Al}_{2} \mathrm{O}_{3}: \mathrm{Cr}_{2} \mathrm{O}_{3}$ solid solution matrix containing $\mathrm{ZrO}_{2}: \mathrm{HfO}_{2}$ solid solution dispersed particles were studied. The results show that the modulus of elasticity, bend strength and fracture toughness 
strongly depend on the volume fraction and size of the dispersed zirconia solid solution particles. From these results it can be concluded that an optimum composite should contain a higher volume fraction of the dispersed zirconia particles with a monoclinic to tetragonal ratio in the range of $1: 1$ to $1: 2$. The strength degradation of the composite with higher amounts of dispersed particles can be minimized by introducing hafnia in solid solution with zirconia.

Composites containing more than $20 \mathrm{~mol} \%$ of $\mathrm{Cr}_{2} \mathrm{O}_{3}$ in the solid solution in the matrix alumina had a thermal conductivity lower than that of partially stabilized zirconia at temperatures higher than $300^{\circ} \mathrm{C}$. Composites were annealed at 1000 and $1200^{\circ} \mathrm{C}$ for more than $300 \mathrm{~h}$ and no degradation of mechanical properties was observed. The results of these studies suggest that these composites are potential candidates for heat engine applications.

\section{ACKNOWLEDGEMENTS}

The authors wish to thank Drs J. S. Wallace, P. F. Becher and R. N. Katz for helpful discussions. The financial support for this investigation was provided by the US Department of Energy, Division of Transportation Energy Conservation; Office of Vehicle and Engine Research and Development, Ceramics Technology for Advanced Heat Engines Programs; administered by the Army Materials Technology Laboratory.

\section{REFERENCES}

1. Katz, R. N. and Lenoe, E. M., Ceramics for light duty diesel engines: a technology assessment, Automotive Technology Development Contractors Coordination Meeting, Dearborn, Michigan, October 1981, 551.

2. Schioler, L. J., Quinn, G. D. and Katz, R. N., Time-temperature dependence of the strength of commercial zirconia ceramics, Proc. 21st Automotive Technology Development Contractors' Coordination Meeting, Dearborn, Michigan, 14-17 November 1983, P-138, 183-91.

3. Claussen, N. E., Fracture toughness of $\mathrm{Al}_{2} \mathrm{O}_{3}$ with an unstabilized $\mathrm{ZrO}_{2}$ dispersed phase, J. Am. Ceram. Soc., 59(1-2) (1976) 49-51.

4. Greve, D., Claussen, N. E., Hasselman, D. P. H. and Youngblood, G. E., Thermal diffusivity/conductivity of alumina with a zirconia dispersed phase, Am. Ceram. Soc. Bull., 56(5) (1977) 514-15.

5. Lange, F. F., Transformation toughening: Part 5. Effect of temperature and alloy on fracture toughness, J. Mat. Sci., 17(1) (1982) 255-63.

6. Kingery, D. W., Bowen, H. K. and Uhlmann, D. R., Introduction to Ceramics, John Wiley, New York, 1976. 
7. Ruh, R., Garrett, H. J., Domagala, T. F. and Tallan, N. M., The system zirconia-hafnia, J. Am. Ceram. Soc., 51(1) (1968) 23-7.

8. Hasselman, D. P. H., Syed, R. and Tien, T. Y., The thermal diffusivity and conductivity of transformation-toughened solid solution of alumina and chromia, J. Mat. Sci., 20 (1985) 2549-56.

9. Tsukuma, K., Kubota, Y. and Nobugai, K., Thermal and mechanical properties of $\mathrm{Y}_{2} \mathrm{O}_{3}$ partially stabilized zirconia, Yogyo-Kyokai-Shi, 92(5) (1984) 233-41.

10. Wurst, J. C. and Nelsen, J. A., Linear intercept technique for measuring grain size in two-phase polycrystalline ceramics, J. Am. Ceram. Soc., 55(2) (1972) 109.

11. Porter, D. L. and Heuer, A. H., Microstructural development in $\mathrm{MgO}$ stabilized zirconia (Mg-PSZ), J. Am. Ceram. Soc., 62(5-6) (1979) 298-305.

12. Subbarao, E. C., Zirconia-an overview, in Advanced Ceramics-Vol. 3, Science and Technology of Zirconia, Eds A. H. Heuer and L. W. Hobbs, American Ceramic Society, Columbus, Ohio, 1981.

13. Brog, T. K., Transformation Toughening in the $\mathrm{Al}_{2} \mathrm{O}_{3}: \mathrm{Cr}_{2} \mathrm{O}_{3} / \mathrm{ZrO}_{2}: \mathrm{HfO}_{2}$ System, PhD Dissertation, University of Michigan, 1986.

14. Chantikul, P., Anstis, G. R., Lawn, B. R. and Marshall, D. B., A critical evaluation of indentation technique for measuring fracture toughness: II. Strength method, J. Am. Ceram. Soc., 64(9) (1981) 539-43.

15. Schioler, L. J., Katz, R. N., Brog, T. K. and Tien, T. Y., Mechanical properties of zirconia-toughened alumina, Ceramic Engineering and Science, 6(7-8) (1985) 822-5.

16. Zener, C. quoted by C. S. Smith, Grains, phases, and interfaces; an interpretation of microstructure, Metals Technol., 15(4); Trans. Met. Soc. AIME, 175, (1948) 15-51.

17. Li, A. K., Sintering and Growth Kinetics of the Matrix Grains and the Dispersed Particles in the $\mathrm{Al}_{2} \mathrm{O}_{3}: \mathrm{Cr}_{2} \mathrm{O}_{3} / \mathrm{ZrO}_{2}: \mathrm{HfO}_{2}$ Composites, $\mathrm{PhD}$ Dissertation, University of Michigan, 1986.

Received 14 April 1986; accepted 6 May 1986 